\title{
Involuntary Billing Production Scheme with Digital Water Measuring Device
}

\author{
Mohanraj R, Balaji. S, John Paul Praveen A.
}

\begin{abstract}
We rely upon water for some parts of our lives. To secure the water and to oversee it monetarily the measure of water devoured ought to be estimated, Traditional water meters are not fit to gauge the real utilization of water. For multistoried structures the utilities and toilets will be situated at better places so it ends up hard to get the real utilization of water. For tackling this issue we are presenting a computerized water meter by which we can get the genuine utilization of every single delta of the level through advanced stream meter and furthermore create the water bill for every level.
\end{abstract}

\section{INTRODUCTION}

Water is one of the most important natural resources that we have today. Because of the global warming the water level is decreasing day by day. In order to protect it we must use it wisely. As we depend on water for our day to day needs like drinking, cooking and many more. And most of the times people forget to close the tap after use. So, if we keep a track on how much water is consumed and depending upon that generate bills then people will turn it off when not in use. In multispeciality flats utilities will be located at different places so sometimes we cannot get the actual consumption of water. In order to solve the problem we are designing a digital water meter using microcontroller to track the water consumed. The bill will be generated automatically without any manual interpretation as it leads to errors. It also has special advantage of detection of open tap, leakage and no flow by which we can avoid the wastage of water to a large extent. We can also monitor the data wirelessly using webpage. If the bill is not paid within a given period of time then the water supply will be shut down. At last this project will help us to save the water effectively and efficiently.
Revised Manuscript Received on July 22, 2019.

Mohanraj R, ECE, Bharath Institute of Higher Education and Research,India. Email: dspmohanraj@gmail.com.

Balaji .S, ECE, Bharath Institute of Higher Education and Research,India. Email: bala.sripathy@gmail.com.

John Paul Praveen, ECE, Bharath Institute of Higher Education and Research,India. Email: johnpaul.embedded@gmail.com

\section{LITERATURE SURVEY}

The most common problem faced by each and everyone is water. So in order to reduce this problem we have to consume water wisely. The mechanical residential water meters which was previously used consist of moving parts such as displacement and velocity water meters. Because of the moving parts we cannot get the actual consumption of water. And also results in failure because the readings are being calculated and taken manually. Some of the recent researches done in the field of water metering is done using IoT and a smartphone app which can be used for bill payment. These can also detect leakage of water. But there are still some modifications that can be done in order to conserve the water more effectively.

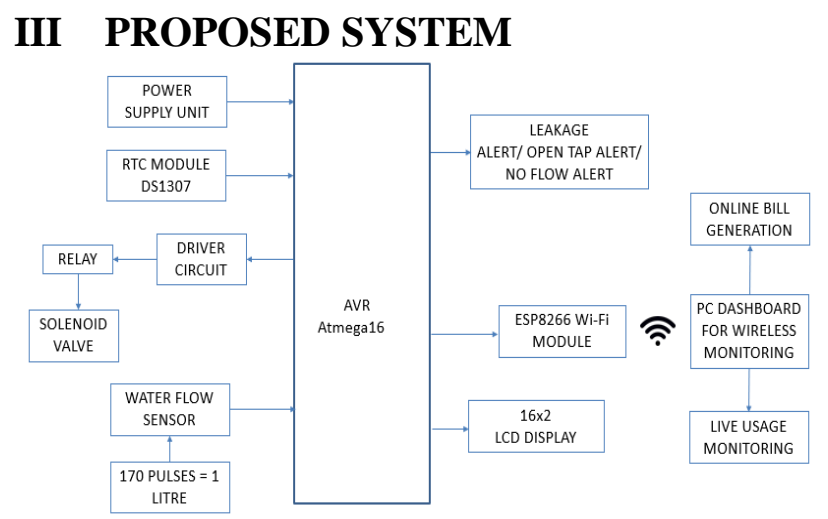

Fig:1 Block Diagram

\section{Power Supply-}

\section{HARDWARE DESCRIPTION}

The following fig shows the circuit of a power supply that converts an ac source to a dc source

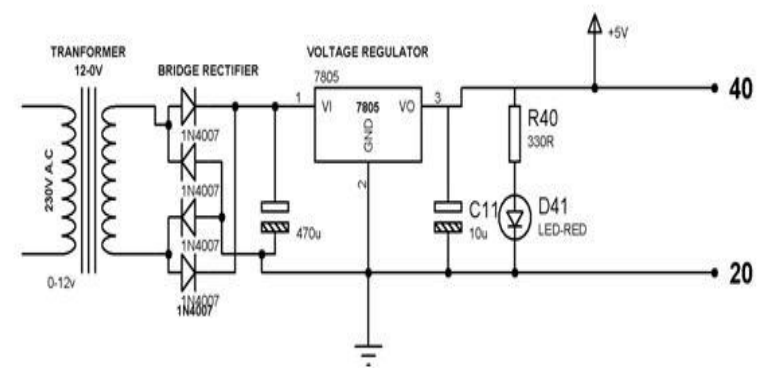

Fig 2: circuit of power supply

Transformer-

In this step down transformer is used. 


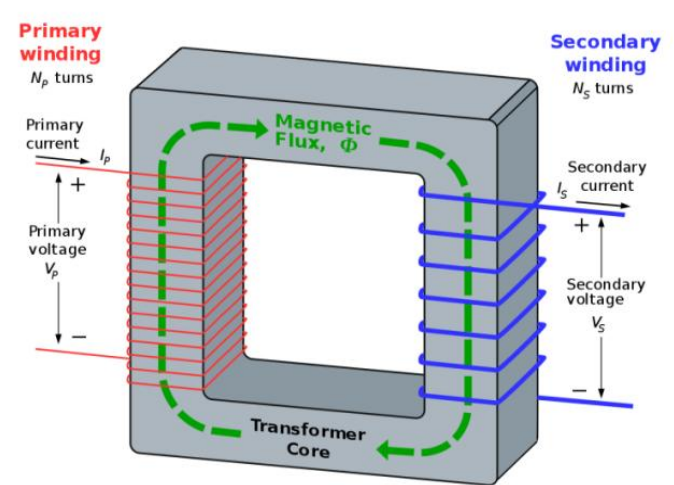

Fig 3: Transformer

Rectifier-A rectifier an electrical contraption that changes over turning stream (AC), which irregularly switches course, to facilitate stream (DC), which streams in only a solitary bearing. The system is known as rectification.

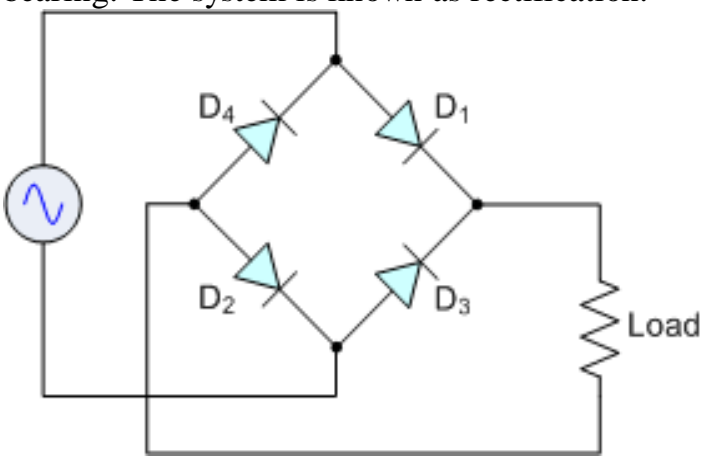

Fig 4: Rectifier

\section{Transistor-Driver Circuit-}

It is composed of a semiconductor material with three terminals for external connection.

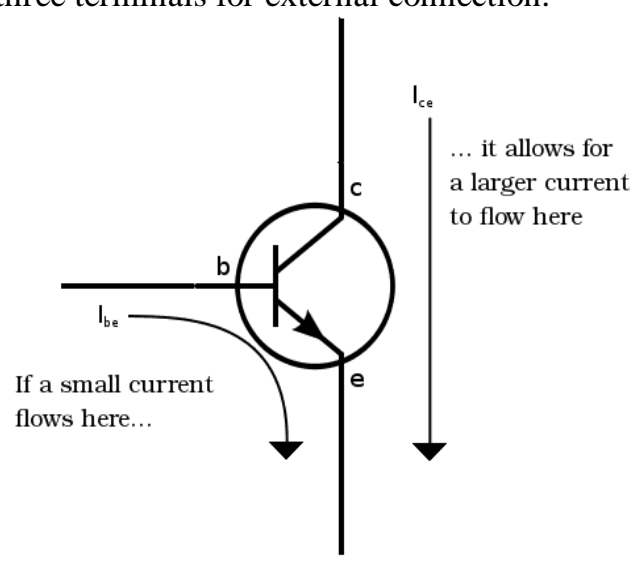

Fig 5: Transistor-Driver Circuit

Water Flow Meter- These are utilized to gauge the volume of water in business and private structures. The stream rate of water is estimated in cubic meters $(\mathrm{m} 3)$ or liters on an electronic or mechanical register. Water stream meters can gauge high temp water, cold water, clean water, filthy water and slurries.

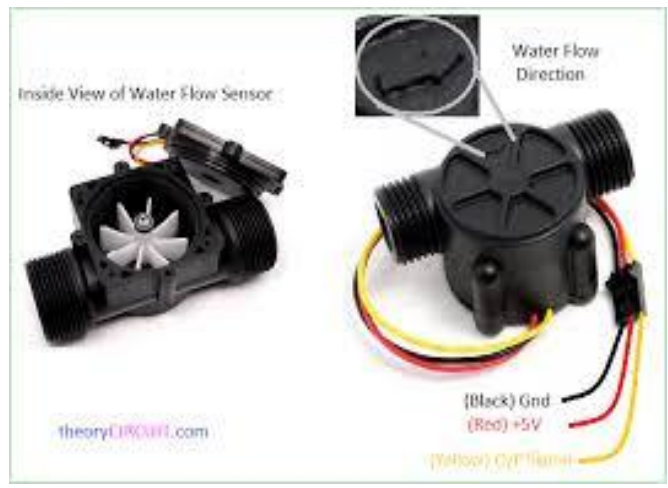

Fig 6: Water Flow Meter

Solenoid Valve- A solenoid valve is an electrically initiated valve, regularly used to control the stream or course of air or fluid in liquid power frameworks. Solenoid valves are utilized in both pneumatic and water driven liquid power frameworks, and regularly in either poppet or spool setups.

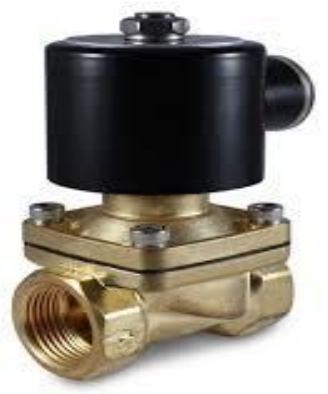

Fig 7:Solenoid Valve

LCD Display- Fluid precious stones are a period of issue whose request is halfway between that of a fluid and that of a gem. It stores the showcase information exchanged from the microcontroller in the interior presentation RAM and creates speck network fluid precious stone driving signs. Each piece information of showcase RAM relates to on/off condition of a dab of a fluid gem show.

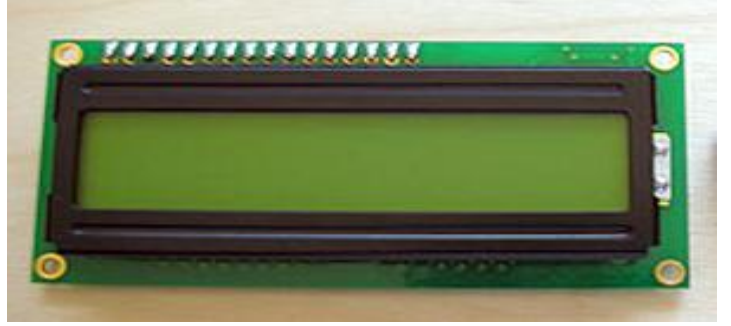

Fig 8: LCD Display

ESP8266 Module- The ESP8266 is a low-cost Wi-Fi chip with full TCP/IP stack and MCU (microcontroller unit).

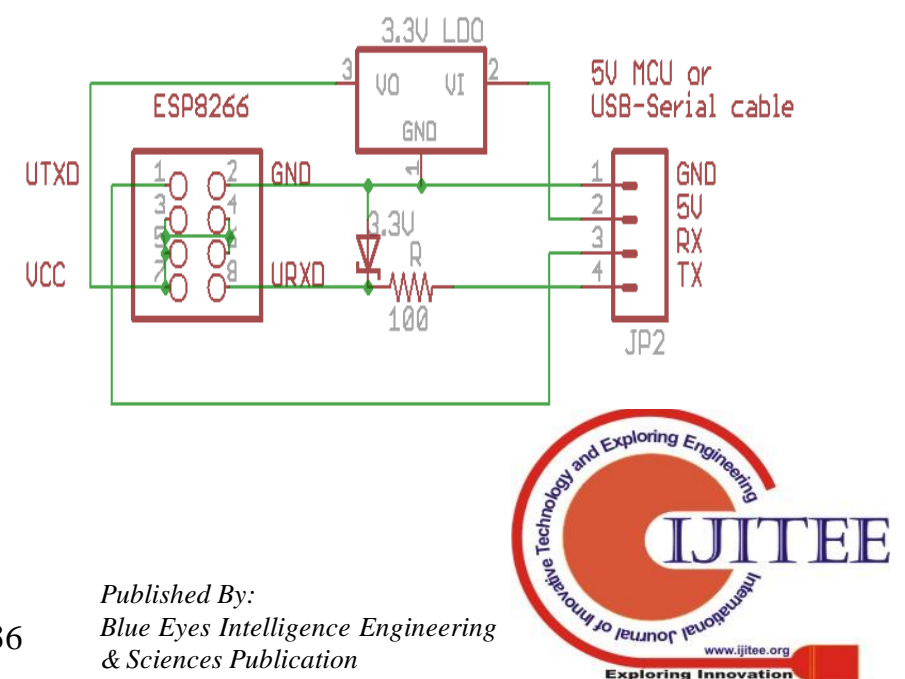




\section{AUTHORS PROFILE}

Fig 9: ESP8266 Module

ESP8266 Wi-Fi Module is a self-contained SOC with integrated TCP/IP protocol stack that can give any microcontroller access to your WiFi network.

\section{SOFTWARE DESCRIPTION}

Proteus- Node.Js- Node.js is an open-source, cross-stage JavaScript run-time condition for executing JavaScript code server-side.

\section{CONCLUSION}

This system allows the automatic calculation of water consumption of each apartment in a building which also leads to fair billing. It enables alarm if an open tap, overflow or a no flow is detected. Wireless monitoring can be done using a webpage. Online generation of bill can be done and if the bill is not paid within a given time limit then the water supply will be shut down. By following all this effective consumption of water can be done.

\section{REFERENCES-}

[1] K.Navi, A. S. Molahosseini, and M. Esmaeildoust, - How to teach residue number system to computer scientists and engineers, IEEE Trans. Educ., Vol. 54, No. 1, pp. 156-163, Feb. 2011.

[2] Y.Wang, X. Song, M. Aboulhamid, and H.Shen,Adder based residue to binary numbers converters for $(2 n-1,2 n, 2 n+1)$, IEEE Trans. Signal Process., Vol. 50, No. 7, pp. 1772-1779, Jul. 2002.

[3] B.Cao,C. H.Chang, and T.Srikanthan, - An efficient everse converter forthe4- moduliset $\{2 n-1,2 n, 2 n+1,22 n+1\}$ based on the new Chinese remainder theorem, ॥ IEEE Trans. Circuits Syst. I, Fundam. Theory Appl., Vol. 50, No. 10, pp. 1296-1303, Oct. 2003.

[4] S. Molahosseini, K.Navi, C. Dadkhah, O.Kavehei, and S. Timarchi, -Efficient reverse converter designs for the new 4 -moduli sets $\{2 n-1,2 n$, $2 \mathrm{n}+1,22 \mathrm{n}+1-1\}$ and $\{2 \mathrm{n}-1,2 \mathrm{n}+1,22 \mathrm{n}, 22 \mathrm{n}+1\}$ based on new CRTs, IEEE Trans. Circuits Syst. I, Reg. Papers, Vol. 57, No. 4, pp. 823-835, Apr. 2010

[5] P.Sowndarya Mala, N.M.Ramalingeswara Rao, V.Sreevani, M.Sai, Analysis and Reduction of high power consumption using parallel prefix adder,

[6] International Journal of Advanced Trends in Computer Science and Engineering,Vol 7,No.6, November -December 2018

[7] S. Molahosseini, S. Sorouri, andA. A. E. Zarandi, - Research challengesin next-generation residue number system architectures, in Proc. IEEE Int. Conf. Comput. Sci. Educ., Jul. 2012, pp.1658-1661.

[8] Omondi and B. Premkumar, Residue Number Systems: Theory and Implementations. London, U.K.: Imperial CollegePress,2007.

[9] Parhami, Computer Arithmetic: Algorithms and Hardware Designs, 2nd ed., New York, NY, USA: Oxford Univ. Press,2010.

[10] Chen and J.Hu, -Energy-efficient digital signal processing via voltageoverscaling-based residue number system,IEEE Trans. Very Large Scale Integr. (VLSI) Syst., Vol. 21, No. 7, pp. 1322-1332, Jul. 2013.

[11] H.Vun, A. B. Premkumar, and W. Zhang, - AnewRNS based DA approach for inner product computation,IEEE Trans. Circuits Syst. I, Reg. Papers, Vol. 60, No. 8, pp. 2139-2152, Aug. 2013.

[12] S. AntãoandL. Sousa, - The CRNS frame work and its application to programmable and reconfigurable cryptography,ACM Trans. Archit. Code Optim., Vol. 9, No. 4, p. 33, Jan. 2013

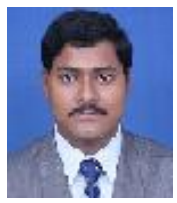

Mohanraj R, Assistant Professor, ECE, Bharath Institute of Higher Education and Research,India.

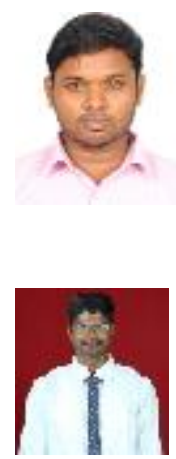

Balaji .S , Assistant Professor , ECE Bharath Institute of Higher Educatio and Research,Chennai,India

John Paul Praveen , Assistant Professor ,ECE, Bharath Institute of Higher Education and Research, Chennai,India. 